\title{
Educação e trabalho: a inserção dos ocupados de nível superior no mercado formal
}

\section{Introdução}

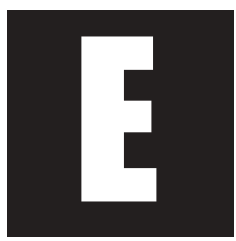

ste artigo apresenta uma análise sobre a inserção dos ocupados com nível superior a partir de dois recortes considerados significativos para a compreensão das desigualdades oriundas do mercado de trabalho: a natureza do vínculo e a inserção regional. O primeiro recorte baseia-se na importância dada pela literatura, a qual aponta uma distinção significativa entre formal/informal, que redunda em fortes diferenciais de renda entre os trabalhadores mais protegidos vis a vis aos trabalhadores sem carteira assinada e por conta-própria. O segundo recorte procura evidenciar as distinções regionais tomando como pressuposto a existência de um forte poder explicativo das dinâmicas sócio-produtivas locais para a configuração das desigualdades sociais. ${ }^{1}$ Assume-se aqui que as distintas dimensões e com-

* Professora do Departamento de Sociologia da USP. Brasil.

** Mestrando em Sociologia. Departamento de Sociologia da USP. Brasil.

1 Esse texto apresenta resultados parciais de um projeto de pesquisa mais amplo intitulado "Desenvolvimento regional e desigualdades sócio-produtivas: tendências recentes, redefinições conceituais e desdobramentos em termos de políticas públicas". Esta pesquisa está sendo desenvolvida no Centro Brasileiro de Análise e Planejamento (CEBRAP) em parceria com o Instituto de Pesquisa Econômica Aplicada (IPEA) e conta com o apoio da Financiadora de Estudos e Projetos (FINEP). Uma primeira versão deste trabalho foi apresentada no GT, Educação e Sociedade $30^{\circ}$ Encontro Anual da ANPOCS, realizado em outubro de 2006. Agradecemos aos coordenadores e participantes do GT a oportunidade para a discussão do trabalho. 
posições dos mercados de trabalho operam como ativos das regiões em termos de atratividade para os investimentos produtivos privados, podendo agravar ou favorecer as condições de competitividade de umas em detrimento de outras (Scott e Storper, 2003). ${ }^{2}$ Com isso, pretende-se captar uma parcela do mercado de trabalho que conseguiu superar dois fortes obstáculos de realização socioeconômica: indivíduos mais educados inseridos no mercado formal.

A reflexão que será aqui apresentada visa contribuir com a literatura sobre educação e mercado de trabalho e, nesse sentido, tem certos pontos de partida em comum com as principais reflexões acerca do tema. Em primeiro lugar, a heterogeneidade da força de trabalho brasileira - em termos educacionais - corresponde à principal fonte de desigualdade salarial, uma vez que o mercado de trabalho traduz uma desigualdade pela outra. Desse modo, quanto mais alto for o valor associado à educação, maior será a desigualdade salarial (Barros, Henrique e Mendonça, 2002). Tal estrutura de distribuição de renda compromete o enfrentamento da estável desigualdade social, considerada um dos principais desafios da nossa sociedade. Embora mais recentemente alguns estudos apontem para uma mudança no padrão de retorno do investimento em educação - dada dinâmica recente do mercado de trabalho -, ela permanece como ativo fundamental e com forte poder explicativo para as desigualdades sociais (Pochmann,2004, Menezes-Filho, 2001).

O segundo aspecto a ser considerado é a expansão do sistema educacional superior e seus efeitos no mercado de trabalho. Dados recentes

\footnotetext{
2 A hipótese principal que norteia nossa pesquisa é que as desigualdades regionais pré-existentes, especialmente no que diz respeito à distribuição e à qualidade dos equipamentos e recursos de ensino, pesquisa e formação profissional, tendem a reforçar as vantagens comparativas de alguns espaços regionais quando se trata da localização de atividades mais intensivas em conhecimento e inovação ou a elas vinculadas de alguma forma por relações de encadeamento (fornecimento e consumo). Por isso optou-se pelo estudo comparativo dos espaços metropolitanos.
} 
sobre características da população ocupada (PNAD-2004) informam que, entre 1992 e 2004, o crescimento desse contingente com mais de 11 anos estudos foi de 137,7\%. Em termos absolutos, o Brasil passou de 11.881.169 ocupados com esse perfil para 28.199.092. Decerto, há muitas questões intrínsecas a esses dados como áreas de formação e distribuição regional dos concluintes, bem como a qualidade do ensino superior oferecido. Mas, resta saber se esses ganhos educacionais significam um ativo de mobilidade e ascensão social e/ou uma estratégia de manutenção de emprego e sobrevivência no mercado de trabalho. Já podemos tratar de uma estratificação ocupacional de nível superior? Tais questões são, sem dúvida, instigantes e merecem investigação.

Um terceiro aspecto diz respeito às mudanças nos processos produtivos - tema fortemente explorado por cientistas sociais e economistas -, e pode ser considerado como uma parte das respostas às questões suscitadas acima. Tanto as mudanças no perfil da força de trabalho quanto na estrutura produtiva modificaram profundamente o ponto-chave da análise da dinâmica do mercado de trabalho: a relação entre oferta e procura.

Discutindo o perfil das novas desigualdades e tomando como ponto de partida as mudanças no sistema produtivo, Saskia Sassen aponta que um dos seus aspectos mais relevantes foi o impacto sobre o equilíbrio ocupacional e industrial dos empregos, surgindo, em termos de demanda, uma nova flexibilidade (empregos temporários e turnos parciais), e em termos de oferta, altos níveis de desemprego que levaram a uma sobre-qualificação para o exercício de determinadas funções. Os estratos médios e baixos da força de trabalho passaram a enfrentar um maior desemprego e conseqüentemente queda de seus salários. Da mesma forma que ocorreu um aumento dos rendimentos em nichos novos e muito qualificados de ocupações acentuando as desigual dades no mercado de trabalho. Entretanto, há que se ponderar que esse efeito - intitulado de bi-polarização - é fruto de 
uma dinâmica complementar mais do que uma oposição. Os setores que cresceram altamente dinâmicos e tecnologicamente adiantados contêm empregos com baixos níveis de remuneração.

Especificamente no caso brasileiro - dado o perfil de sua mão-de-obra -, esse fenômeno acirra a desigualdade salarial no mercado de trabalho. A reestruturação das bases organizacionais das empresas acaba por requerer uma qualificação técnica cada vez maior dos seus funcionários situados no topo da cadeia organizacional, ao mesmo tempo destrói postos de trabalho intermediários que perdem razão de ser em função dos avanços tecnológicos. Quem perde são trabalhadores que possuem uma especialização rígida e com baixa escolaridade, dificultando sua permanência ou reinserção no mercado de trabalho (Alves e Soares, 1996).

A análise que se segue toma como foco os contextos metropolitanos considerados recortes empíricos fundamentais para o entendimento da articulação e do dinamismo das economias regionais. Ela se estrutura a partir de duas dimensões: as características dos ocupados com nível superior e o padrão de absorção desse contingente pelos setores de atividades. Fundamentalmente, busca-se analisar como se organiza o mercado de trabalho formal nos contextos metropolitanos - São Paulo (RMSP), Porto Alegre (RMPA), Salvador (RMSA) - sob o prisma do grau de qualificação dos trabaIhadores (tomada aqui como escolaridade) e qual a sua relação com as estruturas econômicas da qual fazem parte. ${ }^{3}$

Quanto aos procedimentos metodológicos, os dados que serão apresentados foram extraídos da Rais (Relatório Anual de Informação Social). A Rais é uma importante fonte de dados (registros administrativos) sobre o mercado de trabalho formal no Brasil, tendo sido instituída pelo Ministério

3 Como este trabalho é fruto de uma pesquisa em andamento, num primeiro momento, foram selecionados uma região metropolitana das regiões Sul, Sudeste e Nordeste. O projeto de pesquisa como todo contemplará sete regiões metropolitanas. 
do Trabalho (atualmente Ministério do Trabalho e Emprego - MTE), em 1975, e permite análise em série histórica a partir de 1985. A escolha do período a ser estudado pela pesquisa - 1995 a 2002 - norteou-se por sua representatividade em termos de transformações pela qual passou o tecido produtivo brasileiro, propiciado pelas mudanças no plano macro-econômico e no nível micro-organizacional (com a reestruturação da produção nas empresas, terceirização, adoção de novas formas de gestão da mão-deobra, etc.). ${ }^{4}$

Este trabalho toma como ponto de partida a existência de três dimensões que são intercambiáveis, possuem dinâmicas próprias e se ajustam ao problema investigado: o perfil do trabalhador, qualidade dos empregos e a qualidade dos postos de trabalho. A primeira dimensão informa as aquisições e atributos individuais que configuram diferenciais significativos na força de trabalho. A segunda dimensão demarca diferenças através da hierarquização de atividades associadas a certos padrões tecnológicos e organizacionais, e a terceira dimensão refere-se aos atributos do vínculo (formalização) e rendimentos, ou seja, questões associadas a um certo leque de garantias dadas pela qualidade da inserção (Comin, 2003).

Nesse sentido, as agregações de ocupação e da Cnae utilizadas tiveram o propósito, respectivamente, de reunir nas mesmas categorias as ocupações afins em termos sócio-econômicos e em reunir em grupos comuns as atividades cujos padrões produtivos e tecnológicos tendem a ser simila-

4 A escolha considerou questões de ordem operacional da base de dados. Por um lado, a decisão por começar a série em 1995 deve-se ao fato da Rais adotar até 1993 a desagregação dos dados por atividade econômica, segundo a Cnae 85. Tal classificação foi revisada pelo IBGE e a partir de 1994 a Rais passou a seguir a chamada Cnae 95. Por outro, a decisão por terminar a série em 2002 refere-se ao fato da Rais adotar, a partir de 2003, a nova Classificação Brasileira de Ocupações (CBO 2002), de modo que perderia a comparabilidade com a classificação adotada no período anterior (CBO 94) ${ }^{4}$. Assim, para garantir a homogeneidade das informações, ficou estabelecido como período de referência para análise os anos de 1995 a 2002. 
res, no caso da indústria, ou em que há semelhança na natureza do serviço prestado, no caso do setor terciário. ${ }^{5}$

O texto que segue está dividido em três partes. Na primeira, será feita uma breve caracterização das principais tendências do mercado de trabalho no Brasil, com ênfase nos espaços metropolitanos, nos quais serão fornecidos os dados da PNAD-2004. Em seguida, serão apresentados os dados referentes às características gerais do mercado de trabalho formal das regiões metropolitanas selecionadas para posteriormente traçar, na última seção, algumas especificidades acerca da inserção do ocupados com nível superior no mercado de trabalho formal.

\section{Mercado de trabalho no Brasil: tendências recentes}

Antes de iniciar a análise do mercado de trabalho formal e dos ocupados com nível superior será feito, nesta seção, um breve panorama das características do mercado de trabalho no Brasil e das RM's. O intuito é captar de forma mais adequada quais são as especificidades - em termos de educação, posição na ocupação e setor de atividade - dos recortes privilegiados neste estudo. ${ }^{6}$

A tendência geral do mercado de trabalho brasileiro, na última década e meia, apresentou um crescimento na ordem de 28,5\% do total de ocupados (1992-2004). Quanto aos atributos individuais, em termos etários, apresenta uma pequena proporção de ocupados na faixa de 10 a 14 anos, fruto de uma queda de $62,6 \%$, ocorrida nesse período, passando a corresponder a 1,3\% do total de ocupados. Entretanto, permaneceram na PEA via desem-

5 Baseado no estudo de Comin (2003) quanto ao estudo das transformações ocorridas no mercado de trabalho na região metropolitana de São Paulo entre 1989 e 2001, a partir de dados da PED. 6 Uma vez que os dados da RAIS constituem informações específicas sobre o setor formal, para fornecer um quadro geral do mercado de trabalho como um todo, serão apresentados os dados da PNAD-2004. 
prego, com uma taxa de 14,5\%. Em termos educacionais, a proporção da força de trabalho na faixa de 8 a 10 anos de estudo cresceu 77,6\%, e com mais de onze anos de estudos o aumento foi ainda mais significativo, 137,3\%. Em contrapartida, a força de trabalho menos escolarizada vem perdendo espaço no mercado de trabalho, principalmente àqueles com até três anos de estudo (queda de 28,8\%). Outro dado importante, em termos de mudança na dinâmica do mercado de trabalho, diz respeito ao crescimento das práticas informais. Para o ano de 2004, segundo a PNAD, o total de trabalhadores protegidos (empregados com carteira, funcionários públicos e estatutários) correspondia, no Brasil, a 38,9\%.

Já o mercado de trabalho metropolitano que corresponde a quase um terço do total de ocupados do Brasil, ele apresenta, em relação ao total do Brasil, um menor percentual de ocupados nas faixas etárias mais jovens (10-14 e 15-19 anos) sem grandes distinções entre as três regiões metropolitanas investigadas. Em termos educacionais, a distribuição da população ocupada no Brasil metropolitano tem um perfil diferenciado se comparado ao total de ocupados no Brasil: 12,2\% dos ocupados apresentavam mais de quinze anos de escolaridade enquanto para o total do Brasil esse percentual é de 7,9\%. Nas três RM's investigadas, a RMSP apresenta o percentual de 13,3\% seguido da RMPA (11,8\%) e RMSA (7,8\%).

Quanto à posição na ocupação, o Brasil metropolitano e as RM's investigadas concentram um maior percentual de empregados com carteiras assinadas, militares e funcionários públicos estatutários. Dentre as regiões metropolitanas investigadas, a RMSA é a que apresenta menor proporção de trabaIhadores com carteira assinada, mas aproxima-se das demais RM's (superando a RMSP) no percentual de militares e funcionários públicos estatutários. ${ }^{7}$

7 Dado o fato de que os espaços metropolitanos apresentam um menor contingente de trabalhadores na produção para o próprio consumo, trabalhadores na construção para o próprio uso e trabalhadores não remunerados. 
Tabela 1- Pessoas de 10 anos ou mais de idade, ocupadas na semana de referência por posição na ocupação no trabalho principal. Brasil, Brasil Metropolitano e regiões metropolitanas selecionadas, 2004.

\begin{tabular}{|l|c|c|c|c|c|}
\hline & Brasil & $\begin{array}{c}\text { Brasil } \\
\text { Metropolitano }\end{array}$ & RMSA & RMSP & RMPA \\
\hline $\begin{array}{l}\text { Empregados - com carteira de trabalho } \\
\text { assinada* }\end{array}$ & 32,4 & 43,3 & 39,0 & 47,5 & 46,1 \\
$\begin{array}{l}\text { Empregados - militares e funcionários } \\
\text { públicos estatutários }\end{array}$ & 6,6 & 6,7 & 5,9 & 5,0 & 6,9 \\
Empregados sem carteira* & 24,0 & 22,7 & 24,9 & 23,9 & 18,4 \\
Conta própria & 22,0 & 20,6 & 23,2 & 17,9 & 19,5 \\
Empregadores & 4,1 & 4,1 & 3,5 & 4,1 & 5,5 \\
Trabalhadores na produção para & 4,0 & 0,9 & 0,6 & 0,4 & 1,7 \\
o próprio consumo & 0,1 & 0,1 & 0,4 & 0,1 & 0,2 \\
Trabalhadores na construção para & & 1,5 & 2,5 & 1,1 & 1,6 \\
o próprio uso & 7,0 & 100,0 & 100,0 & 100,0 & 100,0 \\
Não remunerados & 100,1 & & & \\
Total & & & & & \\
\hline
\end{tabular}

Fonte: SIDRA-IBGE

* Inclusive trabalhadores domésticos

Por fim, quanto ao setor de atividade, destaca-se a existência de uma nítida linha divisória entre o espaço metropolitano e não metropolitano, dado principalmente pelo forte peso do setor agrícola no total do país e sem muita expressividade no contexto metropolitano. O setor de comércio e reparação se tornam preponderantes no Brasil metropolitano e nas RM's investigadas, exceto na RMPA, na qual a indústria ainda mantém um peso mais significativo. A RMSP, principal pólo industrial do país, apesar dos fenômenos de desindustrialização na região metropolitana, concentra cerca de vinte por cento de sua força de trabalho nesse setor. 
Tabela 2 - Pessoas de 10 anos ou mais de idade, ocupadas na semana de referência por grupamentos de atividade do trabalho principal. Brasil, Brasil Metropolitano e regiões metropolitanas selecionadas, 2004.

\begin{tabular}{|l|c|c|c|c|c|}
\hline \multicolumn{1}{|c|}{ Setor de atividade } & Brasil & $\begin{array}{c}\text { Brasil } \\
\text { Metropolitano }\end{array}$ & RMSA & RMSP & RMPA \\
\hline Agricultura & 21,0 & 2,1 & 2,0 & 0,8 & 4,3 \\
Indústria & 14,7 & 16,5 & 11,4 & 19,8 & 22,4 \\
Construção & 6,3 & 7,0 & 8,7 & 6,2 & 6,9 \\
Comércio e reparação & 17,3 & 20,6 & 21,6 & 20,6 & 18,3 \\
Alojamento e alimentação & 3,6 & 4,9 & 7,1 & 4,6 & 3,6 \\
Transporte, armazenagem e & 4,6 & 6,6 & 6,4 & 6,9 & 5,7 \\
Comunicação & & & & & \\
Administração pública & 5,0 & 4,9 & 5,0 & 3,5 & 5,1 \\
Educação, saúde e serviços sociais & 8,8 & 10,6 & 10,0 & 10,5 & 10,5 \\
Serviços domésticos & 7,7 & 8,7 & 10,5 & 8,0 & 6,8 \\
Outros serviços coletivos, sociais & 4,1 & 5,5 & 6,7 & 4,8 & 4,5 \\
e pessoais & & & & & \\
Outras atividades & 6,8 & 12,1 & 10,2 & 14,2 & 11,5 \\
Atividades mal definidas ou & 0,3 & 0,5 & 0,5 & 0,1 & 0,6 \\
não declaradas & & 100,0 & 100,0 & 100,0 & 100,0 \\
Total & 100,0 & 10,0 \\
\hline
\end{tabular}

Fonte Sidra-IBGE

\section{O mercado de trabalho formal}

Uma das principais preocupações acerca da qualidade e do dinamismo do mercado de trabalho brasileiro diz respeito à formalização dos vínculos que se tornou um diferencial significativo em termos de inserção dos trabalhadores. Há que se reconhecer, entretanto, o alto grau de heterogeneidade da informalidade no Brasil que agrega desde trabalhadores sem carteira em distintos setores de atividade, bem como trabalhadores por conta própria, cujas características, em termos de ocupação, são igualmente diversas. Nesse sentido, o pertencimento ao mundo formal, além de ser um forte ativo no mercado de trabalho, é um importante termôme- 
tro do crescimento econômico do país. Costanzi (2004) analisando a evolução do emprego formal no Brasil, entre 1985 e 2002, apresenta dados importantes que merecem ser destacados. Ele aponta, em primeiro lugar, para a importância que o crescimento econômico acarreta no setor formal. Segundo o autor, para cada incremento de 1\% do PIB real, o estoque de postos de trabalho cresceu 0,87\%. Em segundo lugar, é necessário observar as características dos vínculos criados nesse setor. O estoque de emprego formal, no período analisado, apresentou um aumento da ordem de 40\%. Entretanto, os tipos de contrato de trabalho responsáveis por esse crescimento foram os contratos temporários (taxa de $9 \%$ a.a.) seguido dos contratos dos estatutários (6,4\% a.a.). Os contratos de CLT foram os que apresentaram uma menor taxa de crescimento (2\% a.a.).

Em todas as RM's aqui investigadas, no período 1995-2002, houve uma variação positiva, embora heterogênea, da população ocupada formal. A variação de empregos formais na RMSP foi de 7,7\%, enquanto na RMPA $17,7 \%$ e na RMSA $22,2 \% .^{8}$

Em termos de perfil educacional, observa-se uma significativa redução nas três RM 's investigadas para o percentual de ocupados com menor escolaridade, seguindo uma tendência geral do mercado de trabalho. O principal destaque é o forte crescimento dos ocupados com ensino médio completo (na RMSP esse crescimento foi na ordem de 15 pontos percentuais). Quanto aos ocupados com nível superior, as três regiões metropolitanas apresentaram um discreto aumento desse contingente, sendo que a RMSP apresentava, em 2002, um percentual ligeiramente maior do que as demais (17,0\% 15,7\% e 15,5\% respectivamente).

8 Vale lembrar que esta variação positiva absoluta em todas as RM's do emprego formal não significa que a proporção da população ocupada com vínculos formais esteja aumentando. Pelo contrário, as taxas de formalização se apresentam declinantes no período investigado dada a tendência de crescimento do emprego informal e do desemprego. Ver Neto (2002) para o caso brasileiro e Missio, Vieira e lahn, (2006) e Comin,2003 para as RM's analisadas. 
Tabela 3 - Distribuição dos ocupados formais, segundo grau de instrução, por região metropolitana (em \%)

\begin{tabular}{|l|c|c|c|c|c|c|}
\hline & \multicolumn{2}{|c|}{ RMSP } & \multicolumn{2}{c|}{ RMPA } & \multicolumn{2}{c|}{ RMSA } \\
\hline \multirow{4}{*}{ Fundamental incompleto } & 1995 & 2002 & 1995 & 2002 & 1995 & 2002 \\
\cline { 2 - 7 } & 39,7 & 23,3 & 38,6 & 25,7 & 29,9 & 19,3 \\
Fundamental completo & 23,1 & 23,2 & 23,5 & 26,4 & 20,2 & 20,1 \\
Médio completo & 21,3 & 36,6 & 22,9 & 32,1 & 35,5 & 45 \\
Superior completo & 15,2 & 17,0 & 14,4 & 15,7 & 13,3 & 15,5 \\
Ignorado/não informado & 0,7 & $*$ & 0,6 & $*$ & 1,1 & $*$ \\
Total & 100,1 & 100,0 & 100,0 & 100,0 & 100,0 & 100,0 \\
\hline
\end{tabular}

Fonte - RAIS/MTE, elaboração própria.

A observação da dinâmica setorial contribui para captar quais os setores que mais contribuíram para as variações do emprego formal descritas até então. Em relação a RMSP, embora a variação total da PO apresentada no período seja pequena, a variação intra-setorial é grande. A RMSP foi a que revelou um maior efeito da reestruturação produtiva. Assim, em 1995, a indústria moderna e a indústria tradicional contavam, respectivamente, com 16,2\% e 9,2\% da PO, enquanto em 2002 esse percentual declinou para 11,5\% e 6,6\% respectivamente. O ramo da construção civil apresenta queda da PO de 5,0\% para 3,7\%. Por outro lado, há um crescimento em todos os ramos do setor de serviços nessa região (distributivos, produtivos, sociais e pessoais). Deve-se ter especial atenção para o ramo dos serviços produtivos que se torna o principal absorvedor da população formal ocupada na $\operatorname{RMSP}(22,7 \%) .{ }^{9}$

Na RMPA destaca-se uma perda relativa menor nos setores da indústria - tanto moderna quanto tradicional - e uma presença ainda significativa

9 Serviços Distributivos: transportes e armazenagem, venda de veículos, comércio atacadista e varejista; Serviços Produtivos: serviços creditícios e financeiros especializados em comunicação, administração de valores imobiliários e de imóveis; Serviços Sociais: educação, saúde e serviços comunitários; Serviços Pessoais: de alimentação, domésticos, reparação e limpeza; Governo: serviços de administração pública, forças armadas e polícia. 
da indústria tradicional, vis-a-vis às demais RM's. Outro destaque é o peso significativo do governo nessa região, sendo o responsável pela maior proporção de ocupados. Numa comparação com a RMSP, observa-se que, em primeiro lugar, a indústria moderna na RMPA tem peso relativo no total da PO menor do que o da indústria tradicional, enquanto na RMSP ocorre o inverso. Segundo, o decréscimo de empregos na indústria moderna na RMPA é menor do que ocorre na RMSP (queda de menos de um ponto percentual na RMPA e de cinco na RMSP). Nesse sentido, o peso da desindustrialização do emprego formal foi menor na RMPA.

A estrutura ocupacional da RMSA se distancia das duas anteriores. Em primeiro lugar, a proporção de empregados na indústria (tanto moderna quanto tradicional) é inferior ao das demais regiões investigadas. Em segundo lugar, deve-se lembrar que a RMSA é, dentre as regiões investigadas, a que apresentou o melhor desempenho na geração de empregos formais um crescimento de $22,2 \%$-, fruto do aumento significativo da proporção de ocupados nos serviços produtivos.

Tabela 4 - Distribuição dos ocupados no mercado formal, por ramos de atividade econômica e regiões metropolitanas, 1995-2002.

\begin{tabular}{|l|c|c|c|c|c|c|}
\hline & \multicolumn{2}{|c|}{ RMSP } & \multicolumn{2}{c|}{ RMPOA } & \multicolumn{2}{c|}{ RMSA } \\
\hline \multirow{4}{*}{ Indústria Moderna } & 1995 & 2002 & 1995 & 2002 & 1995 & 2002 \\
\cline { 2 - 7 } Indústria Tradicional & 16,2 & 11,5 & 10,6 & 9,7 & 3,9 & 3,8 \\
Construção Civil & 9,2 & 6,6 & 14,0 & 13,5 & 4,8 & 3,0 \\
Serviços Distributivos & 5,0 & 3,7 & 3,6 & 3,5 & 5,7 & 5,6 \\
ServiçOS Produtivos & 18,3 & 20,6 & 18,7 & 19,3 & 19,3 & 18,4 \\
ServiçOS Sociais & 18,9 & 22,7 & 15,0 & 15,8 & 17,6 & 22,2 \\
ServiçOs Pessoais & 6,9 & 7,4 & 8,9 & 8,5 & 7,7 & 8,0 \\
Governo & 4,1 & 4,3 & 3,5 & 4,0 & 3,5 & 4,8 \\
Outros & 18,8 & 21,1 & 22,8 & 23,1 & 33,9 & 30,4 \\
Ignorado/não informado & 1,8 & 2,1 & 2,3 & 2,8 & 2,2 & 3,7 \\
Total & 0,8 & $*$ & 0,6 & $*$ & 1,3 & $*$ \\
\hline
\end{tabular}

Fonte - RAIS/MTE, elaboração própria 
A diminuição do emprego industrial formal com o conseqüente aumento do emprego em serviços reside nos efeitos da reestruturação produtiva levada a cabo a partir do início da década de 1990. Realizada em ambiente de abertura econômica caracterizou-se por dois movimentos, sendo um de terceirizações, ou seja, de transferência das atividades ${ }^{10}$ não relacionadas ao centro da produção para o terciário; e outro de modernização tecnológica de empresas, que tem como uma de suas características a diminuição do pessoal ocupado sem a diminuição da produção. Deve-se notar que tais argumentos encontram poder explicativo, principalmente para a RMSP, onde o emprego industrial experimentou queda de aproximadamente cinco pontos percentuais, constituindo-se na maior perda de participação relativa entre as RM's analisadas. Vale ressaltar, entretanto, que o recorte analítico desse trabalho nas regiões metropolitanas não permite captar um fenômeno importante ocorrido no estado de São Paulo que foi o deslocamento das atividades industriais para o interior do próprio estado (Comin e Amitrano, 2003).

Tabela 5 - Renda média dos ocupados formais e razão entre renda média dos ocupados formais das RM’s e RMSP (em salários mínimos), 1995 e 2002*.

\begin{tabular}{|l|c|c|c|c|}
\hline & \multicolumn{2}{|c|}{ Renda média } & \multicolumn{2}{c|}{$\begin{array}{r}\text { Razão entre renda média } \\
\text { RM's e RMSP }\end{array}$} \\
\hline & 1995 & 2002 & 1995 & 2002 \\
\hline São Paulo & 7,7 & 6,2 & 100,0 & 100,0 \\
Porto Alegre & 6,7 & 5,3 & 86,4 & 85,5 \\
Salvador & 5,8 & 4,3 & 74,5 & 69,4 \\
\hline
\end{tabular}

Fonte - RAIS/MTE, elaboração própria

*Salário mínimo nominal: dezembro de 1995, R\$ 100,00 e dezembro de 2002, R\$ 200,00 .

10 Atividades como segurança, alimentação e limpeza. 
Em relação aos rendimentos, a RMSP, nos dois anos investigados, apresenta uma renda média superior às demais regiões, principalmente Salvador. ${ }^{11}$ Além disso, observa-se que, pela razão entre as rendas, no período investigado, a distância se manteve praticamente inalterada na RMPA e aumentou significativamente em Salvador. Além das diferenças entre as regiões em termos do valor desses salários, há um peso da dinâmica produtiva local em temos de rendimento. No caso da RMPA, o forte diferencial de renda em relação a RMSP está ligado à indústria tradicional $(0,62 \%)$ e à construção civil $(0,69)$. Sendo que o setor de governo apresenta uma média salarial superior à média da RMSP (1,22). No caso de Salvador, as diferenças mais significativas em relação a RMSP estão na indústria tradicional $(0,53)$ e serviços produtivos $(0,52)$, e a indústria moderna apresenta uma média salarial superior à da RMSP.

Embora não seja metodologicamente possível comparar os dados entre RAIS e PNAD, observa-se na análise do mercado formal características distintas em relação ao mercado de trabalho como um todo. No mundo formal há uma maior proporção de pessoas ocupadas com melhor desempenho educacional, uma menor proporção de ocupados nas faixas etárias mais novas, e apresenta, em média, rendimentos superiores.

\section{Mercado de trabalho formal e os ocupados com nível superior}

Nesta seção serão descritas as características de inserção dos ocupados com nível superior no mercado de trabalho formal, tendo em vista os diferenciais destes em relação ao conjunto total dos ocupados formais apresentados anteriormente.

11 As observações que serão feitas se restringirão à comparação das diferenças salariais entre as regiões metropolitanas investigadas. Não será feita, no escopo deste trabalho, uma análise que pondere se houve queda ou não do poder aquisitivo pelo valor do salário mínimo em 1995 e em 2002. 
Em primeiro lugar, a variação da parcela da população ocupada formal com nível superior, nas regiões metropolitanas investigadas, foi significativamente superior à da população formal como um todo. A RMSP que teve uma variação de $7,7 \%$ no total de ocupados apresentou uma variação de 20,7\% do total de ocupados com nível superior. As demais RM's apresentaram uma variação ainda mais significativa: $27,5 \%$ na RMPA e 30,2\% na RMSA.

Tabela 6 - Variação da população ocupada formal total e com superior completo, por região metropolitana

\begin{tabular}{|l|c|c|}
\hline & Total dos ocupados & $\begin{array}{c}\text { Ocupados com } \\
\text { nível superior }\end{array}$ \\
\hline São Paulo & $1995-2002$ & $1995-2002$ \\
Porto Alegre & 7,7 & 20,7 \\
Salvador & 17,1 & 27,5 \\
\hline
\end{tabular}

Fonte - RAIS/MTE, elaboração própria

No que se refere à distribuição dos ocupados com nível superior por ramo de atividade econômica, os empregados formais com nível superior estão mais concentrados em serviços produtivos e no governo. Aqui, destaca-se a distinção da RMSP nos serviços produtivos com uma concentração superior às demais regiões. Outro dado interessante é a forte predominância do ramo de governo em todas as RM's com destaque para Salvador (62,5\% dos ocupados) e Porto Alegre (58,0\%). Esse fenômeno demonstra que a mão-de-obra de nível superior está associada a um tipo de atividade que é menos afetada pelas dinâmicas sócio-produtivas. Esse dado evidencia um maior dinamismo na RMSP, a qual apresenta uma concentração de ocupados com nível superior na indústria moderna mais significativa que as demais RM's (embora o percentual desse contingente nos setores da indústria destina-se a ser baixo de modo geral). 
Quanto às mudanças ocorridas no período, os quadros são bastante heterogêneos ao compararmos as distintas RM's. Os empregados com nível superior na RMSP declinam seus percentuais na indústria e governo e crescem de forma significativa nos serviços produtivos. A queda nos setores da indústria apresentada por essa região pode estar associada às mudanças descritas anteriormente (deslocamento espacial das indústrias dentro do estado de São Paulo), bem como fruto de alterações na característica do processo produtivo que estabelece com as atividades de ponta outros tipos de vínculo (como prestação de serviços). Nas RM’s de Porto Alegre e Salvador o crescimento ocorre predominantemente no governo. Percebe-se, então, que as dinâmicas regionais em termos de inserção e mudanças ao longo do tempo são bastante distintas, o que reforça a existência da relação entre as dinâmicas sócio-produtivas locais e o perfil da população empregada com nível superior.

$\mathrm{Na}$ tabela anterior observou-se de que forma os empregados com nível superior estavam distribuídos nos ramos de atividades. A tabela a seguir descreve a proporção de empregados com nível superior no interior da cada setor, ou seja, demonstra o "estoque" de ocupados de nível superior em cada ramo de atividade.

Em primeiro lugar, serviços sociais e, principalmente, o governo são os setores que mais agregam essa mão-de-obra nas três RM's investigadas. Isso demonstra que o serviço público e a área social (nos quais estão alocadas saúde e educação) funcionam como a principal porta de entrada no setor formal para esse perfil de ocupados. A RMSP destaca-se, mais uma vez, na análise do período investigado como a única RM a apresentar uma queda na proporção de ocupados com nível superior no governo e a única a apresentar um aumento no percentual desses ocupados nos serviços produtivos. As demais RM's, ao contrário, diminuíram suas proporções nesse setor e apresentaram um crescimento significativo no governo. Em segundo lugar, 
o ramo de serviços pessoais, indústria tradicional, construção civil e serviços distributivos são os que apresentam uma menor proporção de ocupados graduados, chegando a um patamar máximo de 6,5\% de ocupados com nível superior na indústria moderna na RMSP.

Tabela 7 - Proporção de ocupados formais com nível superior completo em cada ramo de atividade, segundo região metropolitana.

\begin{tabular}{|l|c|c|c|c|c|c|}
\hline & \multicolumn{2}{|c|}{ RMSP } & \multicolumn{2}{c|}{ RMPA } & \multicolumn{2}{c|}{ RMSA } \\
\hline \multirow{4}{*}{ Indústria Moderna } & 1995 & 2002 & 1995 & 2002 & 1995 & 2002 \\
\cline { 2 - 7 } Indústria Tradicional & 8,1 & 10,2 & 5,3 & 5,8 & 10,9 & 12,1 \\
Construção Civil & 4,7 & 6,5 & 2,2 & 2,3 & 5,3 & 4,8 \\
Serviços Distributivos & 5,1 & 5,5 & 3,2 & 2,4 & 5,0 & 2,7 \\
ServiçOs Produtivos & 4,3 & 5,6 & 2,9 & 3,1 & 2,4 & 2,8 \\
ServiçOS Sociais & 14,0 & 17,6 & 13,0 & 11,6 & 10,3 & 8,2 \\
ServiçOS Pessoais & 29,4 & 33,1 & 31,1 & 30,2 & 20,3 & 25,0 \\
Governo & 2,0 & 3,1 & 2,1 & 2,1 & 3,2 & 1,5 \\
Outros & 39,0 & 33,4 & 34,1 & 39,6 & 23,6 & 31,9 \\
Ignorado/não informado & 13,9 & 19,4 & 14,8 & 20,2 & 13,3 & 17,4 \\
Total & 0,0 & $*$ & 4,8 & $*$ & 3,9 & $*$ \\
\hline
\end{tabular}

Fonte - RAIS/MTE, elaboração própria

O crescimento da proporção de ocupados com nível superior no mercado formal pode indicar a existência de dois fenômenos que devem ser diferenciados. $\mathrm{O}$ primeiro diz respeito a um processo de modernização tecnológica de determinados ramos de atividades das $\mathrm{RM}^{\prime} \mathrm{s}$, podendo se relacionar com a manutenção/ampliação da competitividade das empresas em contexto de abertura da economia nacional e de reestruturação produtiva. O segundo diz respeito a uma possível tendência de sobrequalificação da força de trabalho em alguns setores, quer dizer, uma tendência na qual o aumento da qualificação da força de trabalho - no caso, obtenção do título de nível superior - está descolada da qualificação requerida em determinados postos de trabalho. Assim, haveria um número crescente de pessoas com 
nível superior inseridas em atividades que não demandam, de fato, tal qualificação (Machado, Oliveira e Carvalho, 2003) e (Monsueto, 2006).

Em termos de renda, destaca-se uma diferença significativa no mercado formal entre os ocupados de nível superior e o total de ocupados, demonstrando que apesar do que foi ponderado anteriormente, a educação tem um peso determinante na renda dos indivíduos nas três RM 's investigadas. Outro dado significativo é que o ensino superior completo contribuiu para diminuir as diferenças salariais entre a RMSP e as demais regiões.

Tabela 8 - Renda média dos ocupados formais com nível superior e razão entre renda média das RM’s e a RMSP (em salários mínimos), 1995 e 2002*.

\begin{tabular}{|l|c|c|c|c|}
\hline & \multicolumn{2}{|c|}{ Renda média } & \multicolumn{2}{c|}{$\begin{array}{r}\text { Razão entre renda média } \\
\text { RM's e RMSP }\end{array}$} \\
\hline & 1995 & 2002 & 1995 & 2002 \\
\hline São Paulo & 15,3 & 14,1 & 100,0 & 100,0 \\
Porto Alegre & 14,3 & 12,6 & 93,0 & 89,4 \\
Salvador & 13,0 & 10,1 & 85,1 & 71,6 \\
\hline
\end{tabular}

Fonte - RAIS/MTE, elaboração própria

*Salário mínimo nominal: dezembro de 1995, R\$ 100,00 e dezembro de 2002, R\$ 200,00 .

Em todos as RM's investigadas os setores de atividade que melhor remuneram são: indústria tradicional, indústria moderna e serviços produtivos, setores cujo desempenho está fortemente associado às dinâmicas sócio-produtivas. Na RMSP do total de ocupados com nível superior no mercado formal, 32,9\% estão nesses três setores. Para a RMPA e para a RMSA, esses percentuais são 17,2\% e 15,6\%, respectivamente. Em contrapartida, os setores que apresentam as menores médias de rendimentos são serviços pessoais, serviços sociais e governo. Na RMSP esses setores correspondem a $56,8 \%$ do total de ocupados com nível superior e nas RMSA e RMPA correspondem a 75,9\% e 74,8\%, respectivamente. Esses dados apontam que as diferenças de distribuição da população ocupada com nível superior nos ramos de atividade geram diferenças em termos de rendimento. 
Tabela 9 - Renda média das ocupações (com nível superior) por ramo de atividade(em salários mínimos), 1995 e 2002*.

\begin{tabular}{|l|c|c|c|c|c|c|}
\hline & \multicolumn{2}{|c|}{ RMSP } & \multicolumn{2}{c|}{ RMPA } & \multicolumn{2}{c|}{ RMSA } \\
\hline Setor & 1995 & 2002 & 1995 & 2002 & 1995 & 2002 \\
\hline Indústria Moderna & 29,6 & 23,3 & 26,4 & 23,0 & 34,6 & 27,1 \\
Indústria Tradicional & 23,5 & 20,0 & 17,4 & 15,8 & 13,7 & 12,4 \\
Construção Civil & 21,7 & 18,3 & 19,4 & 14,6 & 16,8 & 11,8 \\
ServiçOS Distributivos & 19,2 & 16,1 & 15,3 & 11,5 & 12,4 & 11,4 \\
ServiçOs Produtivos & 22,4 & 18,8 & 18,4 & 16,0 & 19,6 & 13,0 \\
Serviços Sociais & 13,7 & 12,4 & 13,7 & 11,2 & 12,1 & 9,8 \\
ServiçOS Pessoais & 13,5 & 9,1 & 8,8 & 6,0 & 6,9 & 6,1 \\
Governo & 9,6 & 10,0 & 12,3 & 11,8 & 10,7 & 8,8 \\
Outros & 14,9 & 12,4 & 16,2 & 11,2 & 11,4 & 10,2 \\
\hline
\end{tabular}

Fonte - RAIS/MTE, elaboração própria

*Salário mínimo nominal: dezembro de 1995, R\$ 100,00 e dezembro de 2002, R\$ 200,00 .

Neste ponto vale destacar a distinção entre setor público e setor privado. A maior concentração de pessoas com nível superior no setor privado é um dos fatores que elevam as diferenças salariais entre as regiões. No caso da RMSA o governo está entre os que pagam menos, mas a proporção desses ocupados neste setor é significativa, 30,4\% em 2002, enquanto na RMSP e RMPA esse percentual é de $21 \%$. O debate acerca dos diferenciais de renda entre setor público e setor privado aponta para uma necessidade de traçar duas diferenciações: a primeira é qualificar o funcionalismo públiCo (municipal, estadual e federal), a segunda é distinguir os níveis de inserção. Belluzzo et alli (2005) analisando as diferenças salariais entre setor público e setor privado aponta que, para os maiores salários das esferas estaduais e municipais, há evidências de que somente os menores salários encontram remuneração superior ao do setor privado, enquanto o restante da distribuição de salários estão abaixo do setor privado. 


\section{Educação e mercado de trabalho: considerações finais}

Este artigo procurou qualificar de que forma a conclusão do ensino superior atua na inserção dos indivíduos no mercado de trabalho. Para isso, tomou como referência um atributo considerado fundamental em termos de qualificação que é o pertencimento ao mundo formal. A combinação qualidade do vínculo e qualidade da força de trabalho - demonstra o peso que essas variáveis têm na produção dos diferenciais de renda no mercado de trabalho.

Embora este texto tenha se dedicado a investigar os ocupados com nível superior completo, na década de noventa, o principal fenômeno educacional foi sem dúvida a expansão do ensino médio. Nesse sentido, há que se considerar que a demanda pelo ensino superior tende a crescer. Castro (1998), analisando o perfil dos concluintes do ensino médio, aponta que a grande maioria conciliou trabalho com estudo durante o curso (60\%), proporção essa que chega a $72 \%$ entre os alunos do turno noturno. Isso evidencia que esses estudantes estão investindo em qualificação. Resta saber se esse investimento se compatibilizará com as demandas do mercado de trabalho por uma força de trabalho mais qualificada.

Seguindo a hipótese de que as dinâmicas sócio-produtivas locais são essenciais para a configuração do mercado de trabalho, foram escolhidas três regiões metropolitanas pertencentes a distintas regiões brasileiras com o intuito de - uma vez controlada a qualidade do trabalhador e do tipo de vínculo - perceber qual o peso das RM's na configuração do mercado de trabalho formal e de que forma elas alocam seus trabalhadores mais qualificados em termos educacionais. Nesse sentido, foi possível perceber que embora algumas características possam ser consideradas comuns a todas as RM's - como, por exemplo, o crescimento do setor de serviços, a importância do setor governamental -, há elementos importantes como o peso 
de cada um desses setores na dinâmica produtiva local e na absorção de ocupados com nível superior que contribuem para o entendimento das diferenças regionais.

\section{Referências}

ALVES, Edgar \& SOARES, Fábio. Ocupação e escolaridade: tendências recentes na grande São Paulo. Textos para discussão, no 428. Rio de Janeiro, IPEA,1996.

BARROS Ricardo Paes, HENRIQUES, Ricardo e MENDONÇA, Rosane. Pelo fim das décadas perdidas: educação e desenvolvimento sustentado no Brasil. Texto para discussão, no 857, Rio de Janeiro, IPEA, 2002.

BELLUZZO, Walter, ANUATTI-NETO, Francisco and PAZELLO, Elaine T. Distribuição de salários e o diferencial público-privado no Brasil. Rev. Bras. Econ., Oct./ Dec. 2005, vol.59, no 4, p.511-533.

CASTRO, Maria Helena G. Avaliação do Sistema Educacional Brasileiro: Tendências e Perspectivas. http://www.inep.gov.br/download/cibec/1998/ titulos_avulsos/avsisteduca.pdf

COMIN, Alvaro "Mudanças na estrutura ocupacional do mercado de trabalho em São Paulo". 2003. Tese (Doutorado em Sociologia) - da Faculdade de Filosofia, Letras e Ciências Humanas, Universidade de São Paulo, São Paulo.

COMIN, Alvaro e AMITRANO, Cláudio. Economia e emprego: a trajetória recente da região metropolitana de São Paulo. Novos Estudos Cebrap, São Paulo, no 66, julho de 2003.

COSTANZI, Rogério. Evolução do emprego formal no Brasil (1985-2003) e implicações para as políticas de geração de emprego e renda. Texto para discussão, Brasília. no 1039, setembro de 2004.

MACHADO, Ana Flavia, OLIVEIRA, Ana Maria e CARVALHO, Nayara. Tipologia da qualificação da força de trabalho: uma proposta a partir da noção de incompatibilidade entre ocupação e escolaridade. Textos para discussão, Belo Horizonte, no 218, CEDEPLAR/FACE/UFMG, agosto de 2003. 
MENEZES-FILHO, Naércio Aquino. A Evolução da educação no Brasil e seu impacto no mercado de trabalho. Departamento de Economia/USP, São Paulo, disponível em www.ifb.com.br/documentos/artigo_naercio.pdf., 2001.

MISSIO, Fabrício, VIEIRA, Rosele e IAHN, Jaicy. Reestruturação produtiva. Plano real e mercado de trabalho: algumas considerações sobre a Região Metropolitana de Porto Alegre. Trabalho apresentado no 30 encontro de economia gaúcha. IN http://www.pucrs.br/eventos/3eeg/Artigos/m19t02.pdf, abril de 2006.

MONSUETO, Sandro EduardoDemanda por cualificación y sub-empleo en Brasil: un análisis de los trabajadores con educación superior. X Jornadas de Economía Crítica, Barcelona, 2006.

NETO, Leonardo Guimarães. As economias regionais e o mercado de trabalho brasileiro dos anos de 1990. In: KON, Anita (org.). Unidade e fragmentação: a questão regional no Brasil. São Paulo: Editora Perspectiva, 1990.

NOZOE, Nelson Hideiki, BIANCHI, Ana Maria e RONDET, Ana Cristina. A nova classificação brasileira de ocupações: anotações de uma pesquisa empírica. São Paulo em Perspectiva, São Paulo, vol. 17, no 3-4, jul./dez. 2003.

PACHECO, Carlos Américo. (1998). "Fragmentação da nação". Instituto de Economia da UNICAMP, Campinas.

POCHMANN, Marcio. Educação e trabalho: como desenvolver uma relação virtuosa? Educação e Sociedade, Campinas, vol.25, no 87, p.383-399, agosto 2004.

SASSEN, Saskia. As novas desigualdades nas cidades. In: As cidades na economia mundial. São Paulo: Studio Nobel, 1994. p.129-152.

SCOTT, Allen e STORPER, Micheal. Regions, Globalization, Development. UCLA. mimeo, 2003. 
Sociologias, Porto Alegre, ano 9, no17, jan./jun. 2007, p. 216-238

\section{Resumo}

O objetivo deste artigo é compreender de que forma a conclusão do ensino superior atua na inserção dos indivíduos no mercado de trabalho. Para isso, tomou como referência um atributo considerado fundamental em termos de qualificação que é o pertencimento ao mundo formal. A partir dos dados da RAIS, procura demonstrar como a combinação qualidade do vínculo/qualidade da força de trabalho exerce um peso significativo em termos dos diferenciais de renda no mercado de trabalho. Além disso, com o intuito de captar o peso das dinâmicas sócio-produtivas locais no funcionamento do mercado de trabalho as questões investigadas foram analisadas em três regiões metropolitanas: São Paulo, Porto Alegre e Salvador.

Palavras-chave: mercado de trabalho formal, RAIS, região metropolitana de São Paulo, região metropolitana de Porto Alegre, região metropolitana de Salvador, nível superior.

Recebido: 05/01/07

Aceite final: 26/02/07 


\section{Education and work: the situation of employed college graduates in the job market}

\section{Márcia Lima e Alexandre Abdal}

This article is aimed at understanding the impact of complete higher education on the situation of individuals in the job market. For that, its reference was a crucial attribute in terms of qualification: belonging to the formal world. Based on RAIS data, it seeks to demonstrate how the combination of quality of legal labor situation and quality of the workforce plays a significant role on income in the job market. Furthermore, in order to verify the weight of local social-productive dynamics in the workings of the job market, the issues investigated were examined in three metropolitan areas: São Paulo, Porto Alegre, and Salvador.

Key words: Formal job market; RAIS, São Paulo metropolitan area, Porto Alegre metropolitan area, Salvador metropolitan area, higher education. 